its particular range of applicability" ? (p. 81). Does not the standard Nyquist theory of stability under feedback (nowhere mentioned) specifically include this case?

How does the "law of experience" on pp. 138-9 guarantee that even a simple machine could be brought "each morning. . . to some standard state" by taking its input through some standardized routine "in the early morning"? Surely the time taken must depend on the machine in question, and the only 'standard state' possible might well be one quite useless to the experimenter (for example, if the machine contained an irreversible counter with nonrecurrent tallies)? Again, how does Shannon's theorem on the capacity of a noisy channel "show that the problem" of the corruption of information in the brain (p. 191) "is a minor one"?

Misleading generalizations of this sort are destructive of one's confidence, and it should be said that there are not too many. But the impression remains that it is the discriminating reader, in search of a new angle on an old subject, rather than the novice in search of a balanced presentation, who can be most confidentily recommended to read this entertaining book.

D. M. MacKaY

\section{BONE METABOLISM}

The Biochemistry and Physiology of Bone Edited by Geoffrey H. Bourne. Pp. xiii +875 . (New York: Academic Press, Inc.; London: Academic Books, Ltd., 1956.) 20 dollars ; $143 s$.

RONE is a specialized connective tissue characterB ized by long branching processes which occupy cavities and fine canals in a hard, dense matrix of bundles of collagenous fibres in an amorphous ground substance impregnated with calcium phosphate complexes. It is not a static tissue but a plastic, actively metabolizing tissue. During the past twentyfive years, there has been a rapid development of new techniques. The present publication is the outgrowth of a belief that the time had come to collect the diverse studies published in a wide variety of journals into one integrated volume. The comprehensiveness of the present treatise by a panel of twenty-eight experts discoursing in some twenty-four chapters has nevertheless a unity despite some degree of overlap which is inevitable in a multi-author publication.

In his preface Dr. Geoffrey H. Bourne, the editor of the volume, points out that Frey in his manual of histology published nearly a hundred years ago summarized what is our present conception of bone when he wrote: "Owing to their hardness and solidity, the bones are peculiarly well adapted for the mechanical construction of the body. ... They serve to protect internal organs, and form systems of levers. ... The bones take part also, to a great extent, in the chemicel occurrences of the organism, owing to the lively interchange of matter going on in them".

The introduction of new histological stains and metal impregnations and new biophysical techniques such as X-ray diffraction, polarization and electron microscopy, and the use of radioactive isotopes to the study of bone tissue, has thrown fresh light on the structure and physiological function of bone tissue. These are described in this most interesting series of contributions.

The organic and inorganic parts of bone together form a marvellous construction on the ultrastructural level, a construction that has good mechanical properties, but also has the ability to incorporate and exchange various ions at a very rapid rate. It serves in this sense to regulate the ionic milieu in the body. This quick pick-up and release of ions by some surfaceexchange phenomena or recrystallization means that a number of radioactive isotopes introduced into the body become localized in the skeleton at specific 'hot. spots' which may cause radiation sickness. One of the contributors points out that in our time, when each individual risks contamination with 'bone-seeking' radioisotopes such as products from uranium or plutonium fission, it is extremely important to study bone structure and physiology from the molecular to the anatomical level. A study of bone may help us to find specifics or principles for the detoxication of the skeleton with respect to radioisotopes. There is a special urgency for such research and this collection of reviews is timely. The text is very clear, fully documented and the illustrations remarkably good.

D. P. Cuthbertson

\section{MORAL CODES AND ETHICAL THEORIES}

\section{Encyclopedia of Morals}

Edited by Vergilius Ferm. (Midcentury Reference Library.) Pp. xi+682. (New York : Philosophical Library, 1956.) 10 dollars.

7 HIS book consists principally of a set of articles, varying in length from two to a dozen pages, on subjects which fall roughly into the following categories: expositions of the main tenets of eminent moral philosophers of all times; descriptions of the main types of ethical theory such as utilitarianism; descriptions of the moral ideals of influential religious and cultural groups such as the Quakers, the Chinese and the Jews; anthropological studies of the moral beliefs and practices of modern primitives such as American Indian tribes. These main articles appear in alphabetical order among a host of shorter articles which have no independent content but refer one to the relevant main articles and take the place of an index.

The main articles, all signed, are the work of a considerable body of American scholars. So far as a single reader of such a work can judge they are fair, clear in style and well proportioned; even when the reader may disagree it will generally be on a debatable point, for there is little sign of culpable ignorance or carelessness. The most obvious lacuna is the absence of any main articles on prominent moral notions and problems. This is presumably deliberate policy and might be defended on the ground that such articles would inevitably be controversial and thus out of keeping with the factual character of the rest. But the price paid is that if one looks up such a key notion of morality as 'conscience' one is simply advised to consult some twenty main articles, some of which refer to conscience only in passing.

This is not primarily a book for the specialist in the fields covered, since he will slways know, or need to know, more on any topic than this book can tell him; though even he will find many things to interest him. But for the reader who might wish to know, accurately but in no great detail, Schopenhauer's views on moral philosophy, the general character of Hindu moral ideals, what Nietzsche said 